\title{
Analisis Spektral Data Curah Hujan di Sulawesi Utara
}

\author{
Novvria Sagita1,2), As'ari2), Wandayantolis 1,2)
}

1) Badan Meteorologi, Klimatologi dan Geofisika

2) Jurusan Fisika, Fakultas MIPA Universitas Sam Ratulangi

\begin{tabular}{l}
\hline K A T A K U N C I \\
\hline Analisis spektral \\
Fast Fourier Transform \\
peta distribusi spasial \\
Curah hujan.
\end{tabular}

\section{KE YW O R D S}

Spectral analysis

Fast Fourier Transform

Spatial distribution map

Rainfall

A B S T R A K
Penelitian ini mengkaji lebih dalam perbedaaan pola curah hujan di
Sulawesi Utara. Penelitian menggunakan data 12 stasiun atau pos
pengamatan curah hujan di Sulawesi Utara dengan menggunakan teknik
Fast Fourier Transform (FFT). Tujuan penelitian ini adalah membuat peta
distribusi spasial periodisitas spektral curah hujan di wilayah Sulawesi
Utara, sehingga dapat dianalisis fenomena cuaca yang mempengaruhi
curah hujan di beberapa wilayah di Sulawesi Utara. Hasil penelitian ini
menunjukkan bahwa Sulawesi Utara diklasifikasikan menjadi 2 tipe
periodisitas curah hujan yang memiliki kekuatan kerapatan spektral
tertinggi dengan periode 36 dasarian dan periode 18 dasarian. Sulawesi
Utara juga diklasifikasikan menjadi 5 tipe periodisitas curah hujan yang
memiliki kekuatan kerapatan spektral tertinggi ke dua dengan periode $3-$
11 dasarian, periode 18 dasarian, periode 36 dasarian, periode $60-110$
dasarian dan periode 359 dasarian.
A B S T R A C T
This research examines more deeply the differences in rainfall
patterns in Northern Sulawesi. This research use the data from 12 stations
or rainfall observation posts in North Sulawesi by using the technique of
Fast Fourier Transform (FFT). The purpose of this research is to create a
spatial distribution map of rainfall spectral periodicity in North Sulawesi in
order to analyze weather phenomena that affect rainfall in some areas in
North Sulawesi. Based on the results of this study, North Sulawesi is
classified into 2 types of rainfall periodicity having the highest spectral
density power with the period of 36 ten-days (dasarian) and the period of
18 ten-days. North Sulawesi is also classified into 5 types of rainfall
periodicity having the second highest spectral density power with the
period of $3-11$ ten-days, the period of 18 ten-days, the period of 36 ten-
days, the period of $60-110$ ten-days and the period of 359 ten-days.

AVAILABLE ONLINE

08 November 2013

\footnotetext{
*Corresponding author: Jurusan Kimia FMIPA UNSRAT, Jl. Kampus Unsrat, Manado, Indonesia 95115; Email address: novvria.sagita@bmkg.go.id Published by FMIPA UNSRAT (2013)
} 


\section{Pendahuluan}

Sulawesi Utara merupakan salah satu wilayah yang memiliki curah hujan yang variatif, sehingga perlu dilakukan kajian untuk meneliti fluktuasi curah hujan dengan menggunakan teknik spektral. Analisis spektral digunakan untuk mengetahui periodisitas dari berulangnya data hujan. Analisis

spektral merupakan suatu metode untuk melakukan transformasi sinyal data dari domain waktu ke domain frekuensi, sehingga kita bisa melihat pola periodiknya untuk kemudian ditentukan jenis pola cuaca yang terlibat ${ }^{[1]}$.

Objek penelitian adalah pola periodisitas spektral data curah hujan di Sulawesi Utara dengan data curah hujan 10 stasiun atau pos pengamatan curah hujan selama periode 2003 hingga 2012 dan 2 pos pengamatan curah hujan periode 2007 hingga 2012.

Tujuan penelitian ini adalah membuat peta distribusi spasial periodisitas spektral curah hujan dengan kekuatan kerapatan spektral tertinggi di wilayah Sulawesi Utara dan periodisitas spektral curah hujan dengan kekuatan kerapatan spektral tertinggi kedua di wilayah Sulawesi Utara.

Cuaca adalah keadaan atau kelakuan atmosfer pada waktu tertentu yang sifatnya berubah-ubah setiap waktu atau dari waktu ke waktu (Kartasapoetra, 1986). Iklim adalah rata-rata keadaan cuaca dalam jangka waktu yang cukup lama, minimal 30 tahun yang sifatnya tetap ${ }^{[2]}$. Cuaca yang terjadi di Indonesia pada umumnya dipengaruhi oleh fenomena - fenomena yang memiliki periode berulangnya seperti Zona Konvergensi Inter Tropis / Inter Tropical Convergence Zone (ITCZ) yang memiliki periode berulang 6 bulan (Hermawan, 2010), Angin monsun yang memiliki periode berulang 12 bulan[1], Osilasi Madden Julian yang memiliki periode berulang 2 hingga 3 bulan[3], Osilasi dua tahunan / Quasi Biennial Oscillation (QBO) yang memiliki periode berulang 20 hingga 32 bulan ${ }^{[4]}$.

Menurut Clayton (1899), adanya periode tahunan dan harian dalam cuaca yang disebabkan oleh eperubahan posisi matahari[5]. Kondisi cuaca sebenarnya memiliki kemungkinan berulang seperti cuaca sebelumnya. Para peneliti meneliti siklus dari unsur cuaca dan iklim yang berulang kembali, maka diperlukan analisis spektral untuk mengetahui periodisitas berulangnya suatu fenomena cuaca dengan metode Fast Fourier Transform (FFT) yang menghasilkan periodogram. Chatfield (1995) menjelaskan bahwa periodogram adalah hasil plotting dari nilai kekuatan kerapatan spektal (KKS) terhadap frekuensi atau periode [6].

\section{Metode}

Data yang digunakan pada penelitian ini adalah data akumulasi curah hujan selama 10 atau 11 hari (dasarian), sehingga satu bulan memiliki 3 dasarian. Data curah hujan yang digunakan 10 stasiun atau pos hujan di Sulawesi Utara selama 10 tahun (2003 - 2012) : Stasiun Meteorologi Sam Ratulangi, Stasiun Geofisika Winangun, Stasiun Maritim Bitung, Pos hujan Airmadidi, Stasiun pengamatan magnet Tondano, Pos hujan Ratahan, Stasiun meteorologi Naha, Pos hujan Pinolosian, Pos hujan Tombatu, Pos hujan Kotabunan. Dua pos hujan selama 6 tahun (2007 - 2012) : Pos hujan Tumpaan, Pos hujan Poigar.

Alat yang digunakan dalam penelitian ini adalah : Software Matlab 10, Software Arc Gis 9.3, Micrososft Excell 2007 dan peta dasar wilayah Sulawesi Utara. Metode yang digunakan untuk memperoleh periodogram dengan menggunakan metode Fast Fourier Transform (FFT).

(1)

$$
\begin{gathered}
x_{t}=a_{0}+\sum_{p=1}^{(N / 2)-1}\left[a_{p} \cos \left(\frac{2 \pi p t}{T}\right)+b_{p} \sin \left(\frac{2 \pi p t}{T}\right)\right] \\
a_{0}=\bar{x} \\
a_{p}=\frac{2\left[\sum x_{t} \cos \left(\frac{2 \pi p t}{T}\right)\right]}{T} \\
b_{p}=\frac{2\left[\sum x_{t} \sin \left(\frac{2 \pi p t}{T}\right)\right]}{T}
\end{gathered}
$$

Persamaan deret Fourier (1) diatas kemudian di invers fungsi waktu (t) ke fungsi frekuensi $(\omega)$ agar memperoleh persamaan Fast Fourier Transform (2) :

$$
x(\omega)=\int_{-\infty}^{\infty} x(t) e^{-i \omega t} d t
$$

Nilai kekuatan kerapatan spektral pada peridogram diperoleh dari :

$$
K K S(\omega)=\frac{T}{2}\left(a_{p}^{2}+b_{p}^{2}\right)
$$

Langkah-langkah kerja yang dilakukan pada penelitian ini adalah : 
1. Data curah hujan ( $\left.I_{c h}\right)$ selama 10 tahun (2003 - 2012) di 10 pos pengamatan curah hujan di Sulawesi Utara diambil di Stasiun Klimatologi Kayuwatu (stasiun tempat pengumpul data).

2. Data disusun dalam bentuk data deret waktu vertikal di software microsoft excell 2007.

3. Data yang hilang (tidak teramati) diisi dengan nilai rata-rata bulan, misal data februari 2007 tidak teramati maka diisi dengan data ratarata curah hujan $\left(I_{c h}\right)$ bulan februari selama 10 tahun $\left(I_{\text {chfeb2002 }}+I_{\text {chfeb2003 }}+\right.$ dst.../ banyaknya data yang tersedia).

4. Hasil olahan langkah 2 dan 3 dimasukkan ke program FFT (lampiran 13) yang dijalankan di software Matlab.

5. Hasil olahan FFT yang dijalankan di software Matlab menghasilkan grafik Periodogram.

6. Grafik periodogram dianalisis untuk mengetahui periodisitas yang memiliki nilai kerapatan spektrum tinggi.

7. Membuat peta distribusi spasial periodisitas spektral yang memiliki nilai kerapatan spektrum tinggi dengan software Arc Gis 9.3.

8. Peta distribusi spasial periodisitas spektral dianalisis untuk menghasilkan kesimpulan.

Langkah - langkah diatas sesuai dengan diagram alir yang tampak pada gambar 1 dibawah ini.

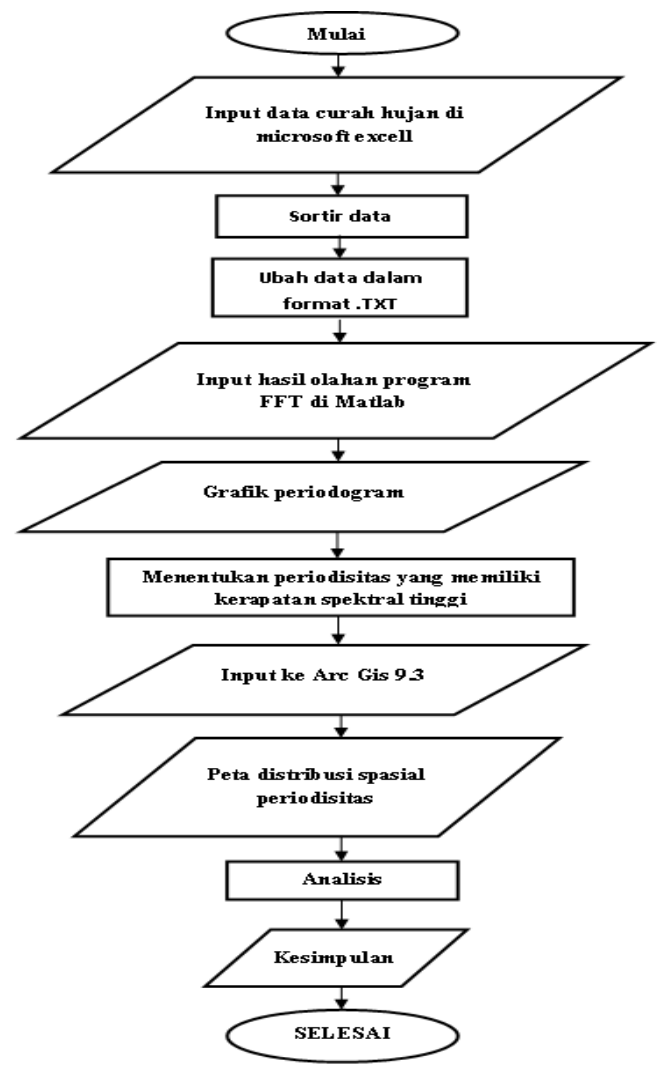

Gambar 1. Diagram alir penelitian. sebuah data yang berulang kembali. Periodogram yang dihasilkan berupa grafik yang menunjukkan nilai kekuatan kerapatan spektral dengan variabel periode sinyal. Kekuatan kerapatan spektral yaitu merupakan nilai kekuatan (daya) sebuah sinyal dapat berulang kembali pada variabel frekuensi atau periode. Periode sinyal hujan menunjukkan waktu yang diperlukan untuk terjadinya satu siklus sinyal data hujan. Periodogram akan menghasilkan periode dengan kekuatan kerapatan spektral tertinggi ke-1 dan tertinggi ke-2.

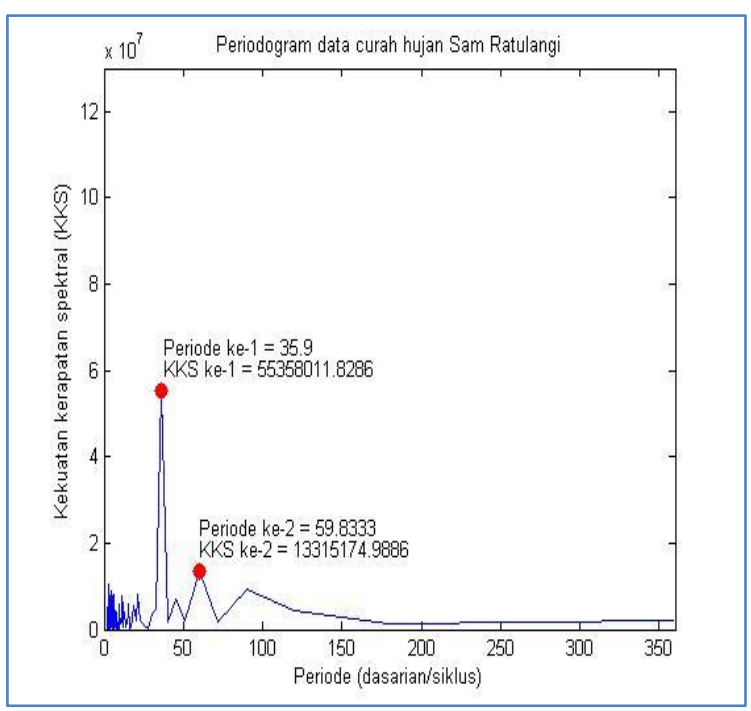

Gambar 2. Periodogram data curah hujan Sam Ratulangi.

Gambar 2 menunjukkan contoh periodogram data curah hujan di stasiun meteorologi Sam Ratulangi. Analisis periodogram untuk data curah hujan di stasiun meteorologi Sam Ratulangi menunjukkan terdapat 2 periodisitas curah hujan yang memiliki nilai kekuatan kerapatan spektral (KKS) yang tertinggi yaitu 36 dasarian dan tertinggi kedua yaitu 18 dasarian. Periode dengan KKS tertinggi di stasiun meteorologi Sam Ratulangi menunjukkan periode data curah hujan yang paling sering berulang. Analisis yang sama kita lakukan pada periodogram pos hujan lainnya.

Fungsi dari periodogram adalah untuk mengetahui perulangan frekuensi atau periode yang dominan dari suatu deret data. Periodogram diaplikasikan pada suatu data curah hujan yang berbentuk data deret waktu dasarian. Data curah hujan dasarian Sulawesi Utara tersebut digunakan sebagai masukan fungsi t pada persamaan deret Fourier yang kemudian di transformasikan dalam fungsi frekuensi $(\omega)$. Pada Gambar 3 adalah contoh data curah hujan dasarian yang memiliki satu periode data berulang setiap 36 dasarian atau 1 tahun.

\section{Hasil dan Pembahasan \\ Analisis Fast Fourier Transform (FFT) merupakan analisis untuk mengetahui periodisistas}




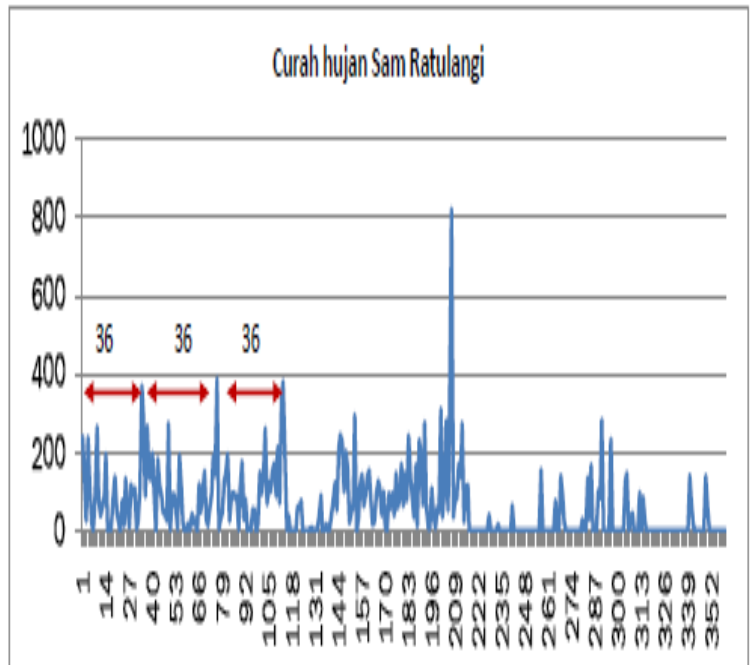

Gambar 3. Data curah hujan dasarian Sam Ratulangi

Analisis periodisitas dengan periodogram juga dilakukan pada 11 stasiun atau pos hujan di Sulawesi Utara yang lain. Hasil periodogram tersebut tampak pada Gambar 4.

Periodogram curah hujan yang ditampilkan pada gambar 2 dan 4 sebagai dasar membuat klasifikasi periode dengan kekuatan kerapatan spektral tertinggi kesatu dan kedua. Pada klasifikasi periode dengan kekuatan kerapatan spektral ke-1 terbagi menjadi 2 tipe yaitu periode sinyal data 36 dasarian dan 18 dasarian. Tipe yang memiliki periode hujan 36 dasarian yaitu Sam Ratulangi, Winangun, Bitung, Air madidi, Ratahan, Naha, Tombatu dan Tanahwangko, Tumpaan dan Poigar. Periode sinyal data hujan 18 dasarian yang meliputi wilayah Tondano dan Kotabunan.

Klasifikasi dengan periode yang memiliki kekuatan kerapatan spektral yang ditampilkan pada Tabel 1 menunjukkan bahwa wilayah Sulawesi Utara didominasi dengan periode sinyal data 36 dasarian atau 1 tahun, sehingga menunjukkan di sebagian besar wilayah Sulawesi Utara dipengaruhi oleh angin monsun. Periode sinyal data akan berulang setelah 36 dasarian atau 1 tahun yang disebut osilasi tahunan. Periode sinyal data 36 dasarian menunjukkan bahwa fase satu gelomabang sinyal data curah hujan tersebut akan berulang kembali setelah 36 dasarian.

Daerah Sulawesi yang berperiode 18 dasarian atau setengah tahun yang disebut osilasi semi tahunan. Pada osilasi tersebut pengaruh dari angin monsunal tidak terlalu dominan pada wilayah tersebut, tapi dipengaruhi fenomena Zona Konvergensi Inter Tropis yang menyebabkan pola curah hujan di wilayah tersebut memiliki dua puncak curah hujan selama setahun.
Tabel 1. Klasifikasi tipe periode sinyal data curah hujan pada kerapatan spektral tertinggi ke-1.

\begin{tabular}{cll}
\hline Tipe & $\begin{array}{l}\text { Periode } \\
\text { (dasarian) }\end{array}$ & Pos Hujan \\
\hline 1 & 36 & $\begin{array}{l}\text { Sam } \\
\text { Winangun, Batulangi, }\end{array}$ \\
& & $\begin{array}{l}\text { Airmadidi, Ratahan, } \\
\text { Naha, Tombatu, } \\
\text { Pinolosian, Poigar } \\
\text { dan Tumpaan } \\
\end{array}$ \\
& 18 & $\begin{array}{l}\text { Tondano } \\
\text { Kotabunan }\end{array}$ \\
\hline
\end{tabular}

Periode sinyal data akan berulang setelah 36 dasarian atau 1 tahun yang disebut osilasi tahunan. Periode sinyal data 36 dasarian menunjukkan bahwa fase satu gelomabang sinyal data curah hujan tersebut akan berulang kembali setelah 36 dasarian. Menurut Aldrian (2003) osilasi tahunan dipengaruhi fenomena monsun Osilasi tahunan (Annual Oscillation), menunjukkanbahwa periode penjalaran gelombangtersebut adalah satu tahun. Osilasi ini dipengaruhi oleh fenomena monsun di wilayah ekuator yang secara dominan juga memengaruhi curah hujandi Indonesia. Pengaruh kuat monsun terhadap curah hujan di Indonesia ditunjukkan dengan terbentuknya pola curah hujan monsunal disebagian besar wilayah Indonesia.

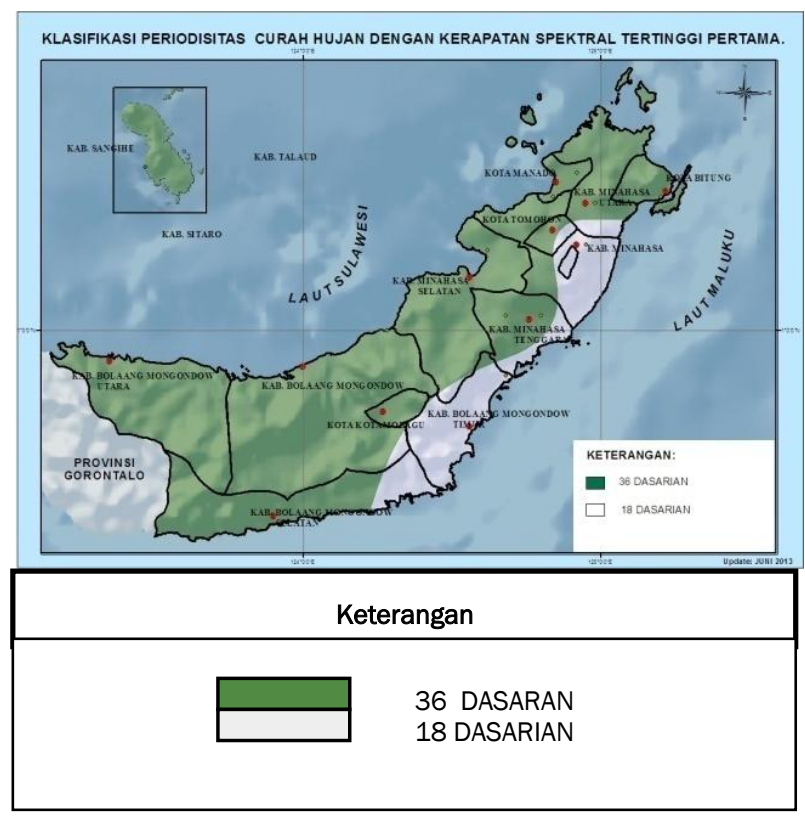

Gambar 5. Klasifikasi periodisitas dengan kekuatan kerapatan spektral tertinggi ke-1 curah hujan di Sulawesi Utara. 
Pada Klasifikasi periode dengan kekuatan kerapatan spektral tertinggi kedua terdapat 5 tipe

klasifikasi yaitu 3 sampai 11 dasarian, 18 dasarian,
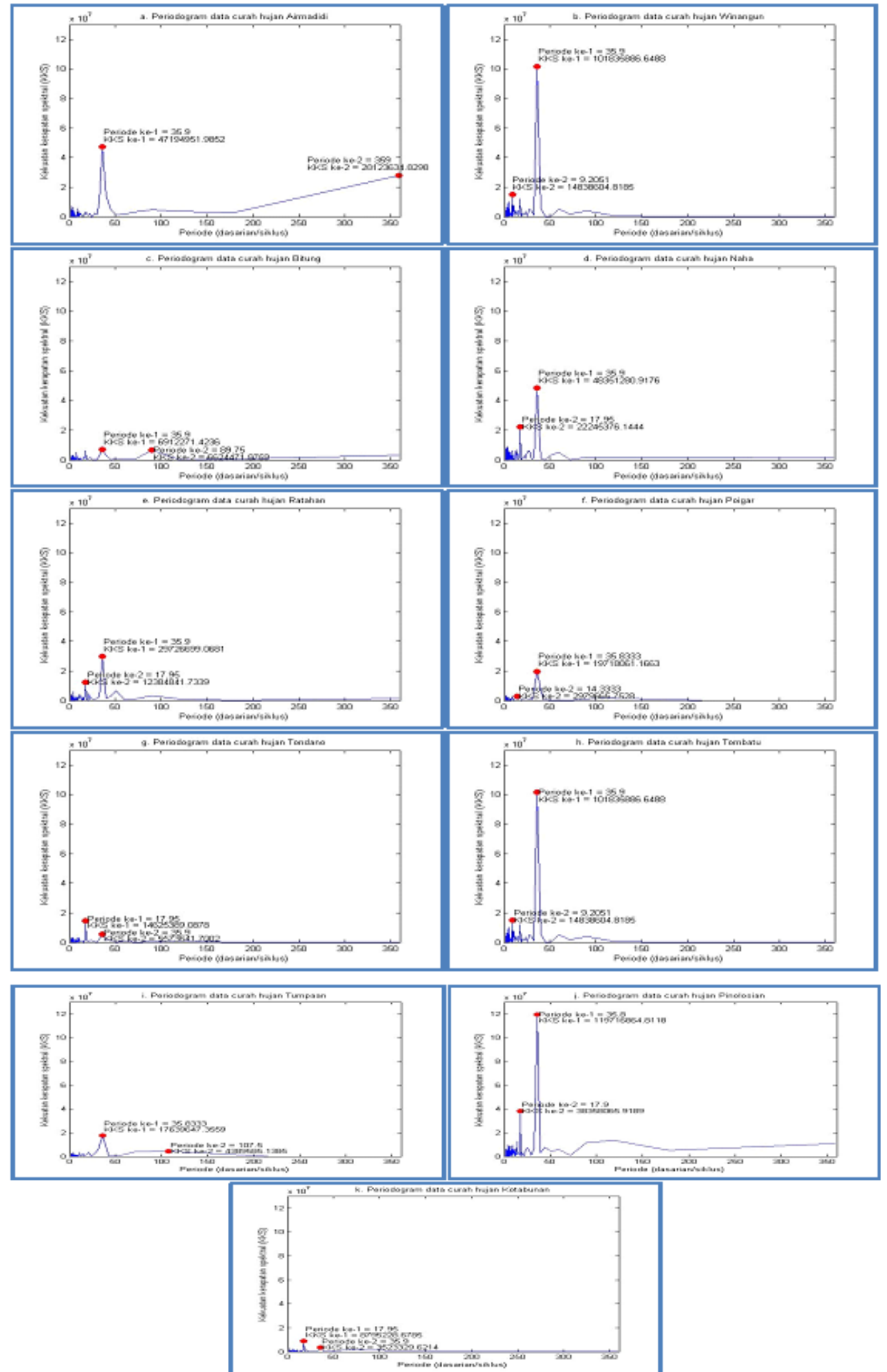

Gambar 4. Periodogram curah hujan stasiun dan pos pengamatan curah hujan Sulawesi Utara (a) Airmadidi, (b) Winangun,(c) Bitung, (d) Naha, (e) Ratahan, (f) Poigar, (g) Tondano, (h) Tombatu (i) Tumpaan, (j) Pinolosian,(k) Kotabunan. 
36 dasarian, 60 hingga 110 dasarian dan 359 dasarian. Hal tersebut ditampilkan pada Tabel 2 dibawah ini.

\begin{tabular}{|c|c|c|}
\hline Tipe & $\begin{array}{l}\text { Periode } \\
\text { (dasarian) }\end{array}$ & Pos Hujan \\
\hline 1 & 3-11 & $\begin{array}{l}\text { Poigar, } \\
\text { Tombatu }\end{array}$ \\
\hline 2 & 18 & $\begin{array}{l}\text { Naha, Ratahan, } \\
\text { Pinolosian }\end{array}$ \\
\hline 3 & 36 & Kotabunan, Tondano \\
\hline 4 & $60-110$ & $\begin{array}{l}\text { Samratulangi,Bitung, } \\
\text { Tumpaan }\end{array}$ \\
\hline 5 & 359 & Airmadidi \\
\hline
\end{tabular}

Tabel 1. Klasifikasi tipe periode sinyal data curah hujan pada kerapatan spektral tertinggi ke-1.

Pada klasifikasi periodisitas dengan kekuatan kerapatan spektral tertinggi ke-2 lebih banyak dari pada klasifikasi kerapatan spektral tertinggi ke-1, hal ini disebabkan fenomena dan topografi masingmasing pos dan stasiun pengamatan curah hujan berbeda antara yang satu dengan yang lain. Tipe 3 sampai 11 dasarian meliputi Winangun, Poigar dan Tombatu. Tipe 18 dasarian meliputi Naha, Ratahan, dan Tanahwangko. Tipe 36 dasarian meliputi Kotabunan dan Tondano. Tipe 60 dasarian meliputi Samratulangi. Tipe 90 dasarian meliputi Bitung. Tipe 359 dasarian meliputi Airmadidi.

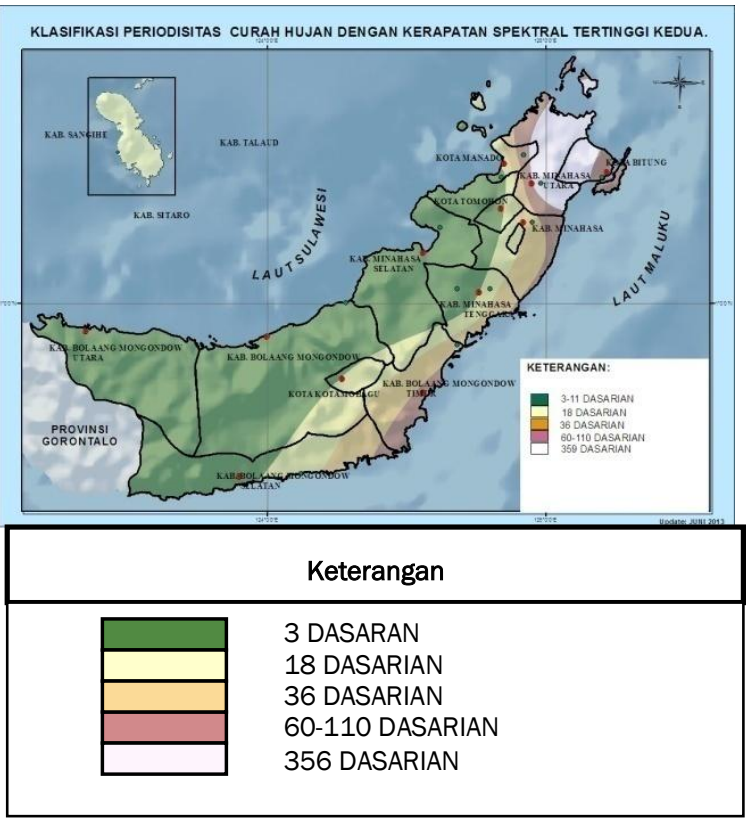

Gambar 6. Klasifikasi periodisitas dengan kekuatan kerapatan spektral tertinggi ke-2 curah hujan di Sulawesi Utara.
Pada Gambar 6 menunjukkan wilayah yang memiliki periodisitas curah hujan 3 sampai 11 dasarian meliputi sebagian besar wilayah Sulawesi Utara yaitu Kabupaten Bolaang Mongondow Utara, Kabupaten Bolaang Mongondow, kota Kotamobagu, kabupaten Minahasa Selatan, Kota Tomohon, sebagian kota Manado, sebagian Kabupaten Minahasa Tenggara, sebagian Kabupaten Bolaang Mongondow Selatan dan sebagian Kabupaten Bolaang Mongondow Timur. Wilayah yang memiliki periodisitas curah hujan 18 dasarian meliputi sebagian kota Manado, sebagian Kabupaten Minahasa Tenggara, sebagian Kabupaten Bolaang Mongondow Selatan dan sebagian Kabupaten Bolaang Mongondow Timur, sebagian kota Manado, sebagian Kabupaten Minahasa, dan Kabupaten Sangihe. Wilayah yang memiliki periodisitas 36 dasarian meliputi sebagian kota Manado, sebagian Kabupaten Minahasa Tenggara, sebagian Kabupaten Bolaang Mongondow Selatan dan sebagian Kabupaten Bolaang Mongondow Timur, sebagian kota Manado,dan sebagian Kabupaten Minahasa.

Wilayah yang memiliki periodisitas 60 hingga 110 dasarian meliputi sebagian Kabupaten Bolaang Mongondow Selatan, sebagian kabupaten Bolaang Mongondow Timur, sebagian Kabupaten Minahasa Tenggara, dan sebagian Kabupaten Minahasa. Wilayah yang memiliki periodisitas curah hujan 359 dasarian meliputi sebagian Kabupaten Minahasa Utara dan kota Bitung.

Wilayah yang memiliki periodisitas curah hujan 3 sampai 11 dasarian dipengaruhi oleh fenomena osilasi Madden Julian karena siklus terjadinya MJO kisaran 3 bulanan. Fenomena osilasi Madden Julian menyebabkan adanya konveksi yang kuat dan berosiliasi bergerak dari wilayah barat ke timur. Fenomena osilasi Madden Julian menyebabkan curah hujan yang tinggi di suatu wilayah. Wilayah yang memiliki periodisitas curah hujan 18 dasarian atau 6 bulanan dipengaruhi oleh fenomena Zona Konvergensi Inter Tropis (ITCZ). Fenomena ITCZ memiliki siklus 6 bulanan karena dipengaruhi gerak semu matahari. ITCZ bergerak dari selatan ke utara dan dari utara ke selatan. Wilayah yang memiliki periodisitas curah hujan 36 dasarian dipengaruhi angin monsunal yang memiliki grafik curah hujan normal bebentuk seperti huruf "V". Periodisitas curah hujan 60 sampai 110 dasarian dipengaruhi fenomena Osilasi dua tahunan (QBO), dimana siklus QBO adalahan kisaran 24 sampai 30 bulan. QBO disebabkan oleh osilasi zonal yang berubah secara bergantian dari angin baratan ke angin timuran. 
3.

\section{Kesimpulan}

Telah dihasilkan peta distribusi spasial periodisitas spektral wilayah Sulawesi Utara yang terklasifikasikan menjadi :

1. Dua tipe periodisitas curah hujan yang memiliki kekuatan kerapatan spektral tertinggi dengan periode 36 dasarian (satu tahun) yang disebut osilasi tahunan dan periode 18 dasarian (setengah tahun) yang disebut osilasi semi tahunan

2. Lima tipe periodisitas curah hujan yang memiliki kekuatan kerapatan spektral tertinggi ke dua dengan periode 3-11 dasarian, periode 18 dasarian, periode 36 dasarian, periode 60 - 110 dasarian dan periode 359 dasarian.

Daftar Pustaka

[1] Hermawan, Eddy. 2010. Pengelompokan Pola
Curah Hujan Yang Terjadi Di Beberapa Kawasan P.Sumatera Berbasis Hasil Analisis Teknik Spektral. jurnal bmkg. Vol. 11 No. 11 Tahun 2010: 75-78.

[2] Kartasapoetra, G.A. 1986. Klimatologi. P T. Bina Aksara. Jakarta.

[3] Anonymous. 2013. Siklus MJO. www.meted.ucar.edutropicaltextbook 2nd_edition media graphicsMJO_cycle_ 1971_translated_to_WH2004.jpg [25 Januari 2013].

[4] Sathiyamurthy V, K. Mohanakumar (2002) Characteristics of tropical biennial oscillation and its possible association with Stratospheric QBO, Geophys Res Lett, 7: 669672.

[5] Clayton, H. H. 1899. Investigation on Periodicity in the Weather. American of Academy of Arts \& Sciences. Vol.34 No. 22: 599 - 618.

[6] Chatfield, C.1995. The Analysis Of Time Series An Introduction. Chapman \& Hall. New York. 